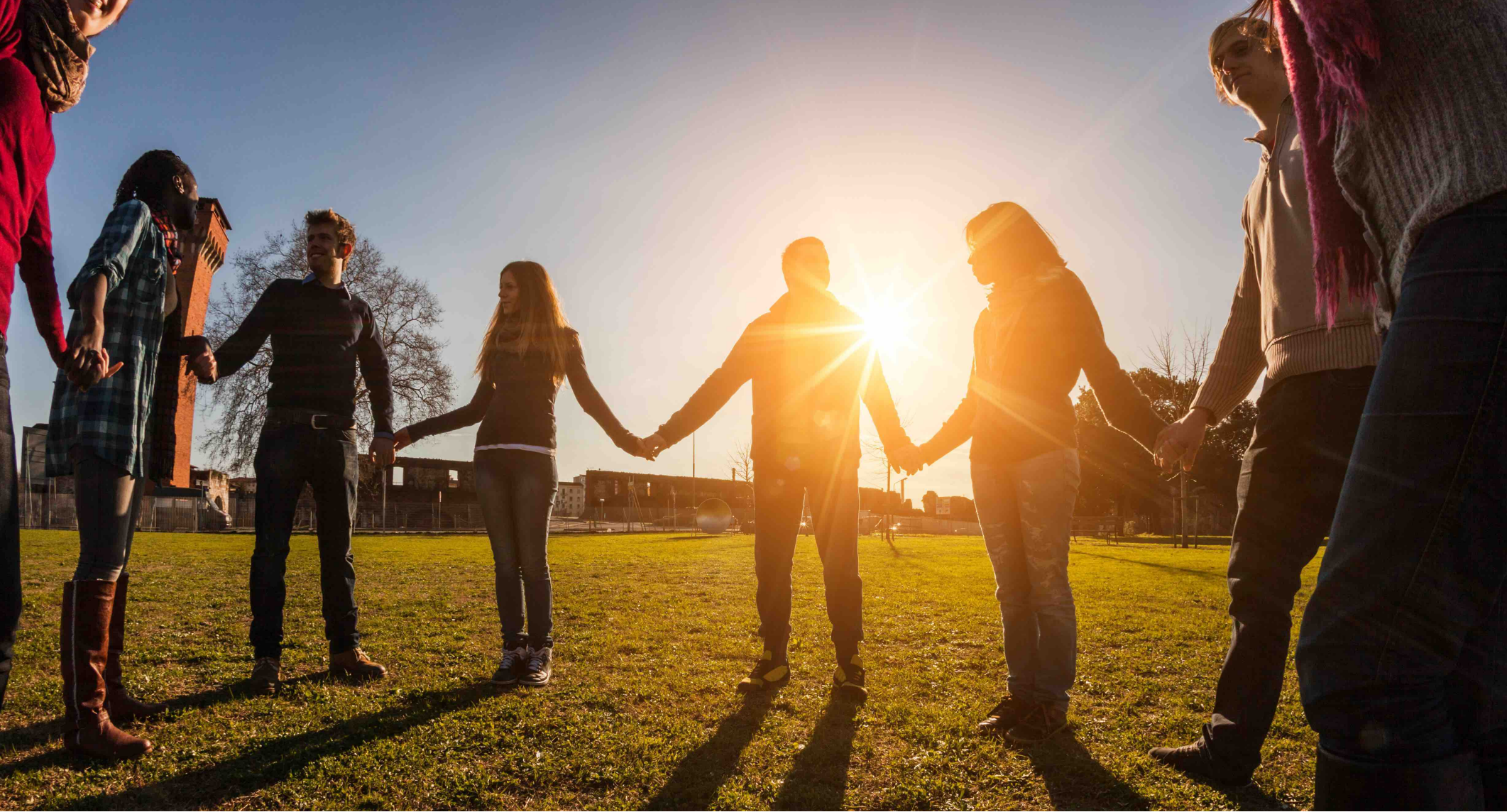

Reflections

\title{
Karate Chops and Kitchen Tools: My experience learning new skills alongside youth with special needs at Montreal's Friendship Circle
}

Josie Cipolla ${ }^{1}$

MJM 2017 17(2)

*Names have been changed to respect the individuals' privacy

“Hi, what's your name?"

I had arrived early for my first experience volunteering at the weekly Cooking and Karate activity at The Friendship Circle in Montreal, made possible through the Community Health Alliance Project (CHAP) course during my second year in McGill Medicine. Its aim was to expose us to how social determinants of health impact different vulnerable populations' access to healthcare.

${ }^{1}$ Faculty of Medicine, McGill University, Montréal, Canada. Corresponding Author: Josie Cipolla, email josie.cipolla@mail.mcgill.ca.
At The Friendship Circle, youth with special needs could find friendship through participation in recreational activities that promote inclusion and support. I still remember meeting Ashley on my first day: a sweet fifteen-year old girl who approached me immediately, happily demanding to know who the new face was.

"I'm Josie," I replied, already feeling welcomed by her greeting. "So nice to meet you. What's your name?" We shared a few seconds of eye contact as I waited for her reply in kind. Instead, she was off, with 
a big smile, to greet the next volunteer that had just walked in the door: "Hi, what is your name?"

I later learned from another volunteer that eye contact and the simple act of greeting someone was a huge milestone in Ashley's social development. It was only recently that she began to greet people while making eye contact. Just a few months ago, she wouldn't initiate that interaction or respond to it at all. That social custom of a friendly greeting is overlooked by many of us. For Ashley, achieving it meant significant progress in how she engaged with others. In my first few minutes of arrival, I had witnessed how uniquely this program was able to meet her specific needs. By caring for Ashley as a whole person, her participation at the Friendship Circle benefited her the way it might help others keep active or share a meal with loved ones.

That was the first of many moments during which I would see the personalized care and support participants of this program received daily. As a volunteer, I saw The Friendship Circle address the barriers to healthcare that young people with special needs face by tapping into a resource that isn't always considered when thinking of traditional healthcare: peer support. The act of attending a social activity and being paired up with a volunteer "buddy," as we were fondly referred to, worked to counter feelings of marginalization and isolation. Such feelings have been shown to further negatively impact the physical and mental health of a person with challenges $(1,2)$.

When she attended a Cooking and Karate class, Ashley was no longer limited by being labelled as a "person with special needs." She, like myself and the other participants, was there to learn new skills, in an environment conducive to helping her also reach personal milestones of communication. At the same time, her needs did not hinder her from learning how to bake lemon cookies or do jumping jacks to warmup for karate among friends. What is at the heart of The Friendship Circle's mission is the idea that through friendship, you are dissolving stigma and empowering the vulnerable to ultimately provide care to their whole person.

The literature is clear, and frankly, repetitive: persons with special needs don't have equal access to healthcare and public services. Unequal access can stem from a lack of a sufficient number of available services, lack of the right type of service, or a complete lack of necessary services altogether.
Charlton and colleagues (2017) describe the surveyed barriers that most commonly prevented families in New Brunswick from accessing health and community services, and their findings echo work done by Lindley et al. (2016) in the United States and Doig et al. (2009) in other Canadian provinces $(3,4,5)$. These barriers are a function of the availability of services in a person's hometown, the organizational limitations of available staff and volunteers, and the financial limitations from the family's perspective as well as from the funding perspective. The more pervasive these limitations are, the greater the obstacles families face in getting the necessary care for their children.

In speaking with some parents of the participants of The Friendship Circle, many of them shared the sentiment that there were not many other services in the city that provided their child with the same variety and frequency of social activities. They also expressed from their experience that limitations in services for people with special needs had more to do with the absence of care for social and emotional health, rather than for physical health. The feeling that echoed across our interactions was one of relief for the existence of this social mission that provided so much in improving their children's quality of life. A program that focused on aspects of care beyond the countless medical follow-ups and referrals, a program that focused on community.

Personalizing care for this diverse community of young people required that I learn how to adapt my approach with each person. Every week I had a new buddy with specific challenges and needs, but all were equal in their willingness to form a connection in their own unique way. The reality of different communication styles among the participants was something I had to quickly pick up on at the start of each evening. If a certain approach did not work, it was an opportunity to try a different one.

Take Taylor for instance: I was paired up with him one evening when he told me that he did not like karate and so he never joined in. Trying to get him involved even in a minimal way, I suggested we at least sit together and watch the others. He agreed, but any further attempts at getting him to join in were unsuccessful. At this point, I also noticed that he had been carrying a toy bear since he arrived, and so I thought using this might be a way to help encourage him to participate: "What is your bear's name, Taylor?"

$$
\text { "Honey," he replied. }
$$


I asked if Honey might want to join the karate class instead. He thought about it for a moment, and then started to help Honey the Bear follow the instructor's moves. He got up and stood alongside the other teens and participated in his own way, but participated nonetheless.

Another buddy, Fred, was a fourteen-year-old boy whose fascination with all things dangerous (fire, sharp objects and poor health habits, for example) led him to fixate on talking about such topics instead of participating in the activities. By trying to validate his comments but reformulating them for him to reinforce positive thoughts ("yes, smoking is bad for you, but did you know karate is good for you?"), he slowly warmed up to the idea of joining in the activities.

I learned so much in trying to find the best ways to reach through to my buddies. The ultimate task at hand was not to help them perfect a karate chop or use a whisk (though those were welcomed bonuses), but to meet a need for social interaction in whatever way that worked for them. My interactions with buddies like Ashley, Taylor and Fred have taught me more about the breadth of needs a person can have. As medical students, our training hones a gut instinct to question what condition a patient's presenting symptoms suggest, but these lessons were taught without ever divulging anyone's medical diagnosis. We seem to be on a constant quest to come up with a plausible mechanism as the foundation for understanding a person's problem. While there are contexts in which that is necessary and vital, there are other contexts in which it makes no difference at all. My CHAP experience opened my eyes to the healing aspects of peer support and how it does not demand adherence to protocols or doses in order to make a difference.

By having a peer by their side, each young person was empowered to approach the social activities in the best way they knew how, which, at the end of the day, resulted in a collective happiness for all those involved. Maybe each smile reflected a feeling of accomplishment for that evening, as Ashley so rightfully earned with her joyful greetings. Maybe it was in regard to having connected with a buddy on a common interest, or maybe it resulted from not being told they were different or incapable but instead were included and engaged. In any case, the empowerment has been made possible through access to a place that works every day to close that divide.

After all, how does the saying go? An ounce of prevention is worth a pound of cure? Access to peer support for Ashley, Taylor, and Fred continues to help them flourish by meeting their needs for genuine human connection, and l'd say that it is worth just as much to whole-person care as any heart-warming chicken noodle soup or prescribed exercise routine can claim.

\section{References}

1. Ahlers, KP, Gabrielsen, TP, Lewis, D, Brady, AM, \& Litchford, A. Supporting individuals with autism spectrum disorder in understanding and coping with complex social emotional issues. School Psychology International [Internet]. 2017; 38(6):586-607. Available from: http://dx.doi.org/10.1177/0143034317719942

2. Musher, DA. Inclusion and attitudes of adolescents in a camp setting. [Internet]. 2016. Available from: https://search-proquestcom.proxy3.library.mcgill.ca/docview/1826530766?acco untid $=12339$

3. Charlton P, Azar R, Luke A, Doucet S, Montelpare W, Nagel D, et al. Falling through the cracks: Barriers to accessing services for children with complex health conditions and their families in New Brunswick. Journal of New Brunswick Studies. 2017; 8:133-158.

4. Lindly OJ, Chavez AE, Zuckerman KE. Unmet Health Services Needs Among US Children with Developmental Disabilities: Associations with Family Impact and Child Functioning. J Dev Behav Pediatr [Internet]. 2016; 37(9):712-723. doi: 10.1097/DBP.0000000000000363

5. Doig JL, McLennan JD, Urichuk L. 'Jumping through hoops': parents' experiences with seeking respite care for children with special needs. Child: care, health and development. 2009; 35(2):234-242. 